\title{
Elevated transaminases during medical treatment of acromegaly: a review of the German pegvisomant surveillance experience and a report of a patient with histologically proven chronic mild active hepatitis
}

\author{
H Biering ${ }^{1}$, B Saller ${ }^{4, *}, \mathrm{~J} \mathrm{Bauditz}^{1}, \mathrm{M} \mathrm{Pirlich}^{1}$, B Rudolph ${ }^{2}$, A Johne ${ }^{3}$, M Buchfelder $^{5, *}, \mathrm{~K} \mathrm{Mann}^{6, *}, \mathrm{M} \mathrm{Droste}^{7, *}$, \\ I Schreiber ${ }^{4}$, H Lochs ${ }^{1}$ and C J Strasburger ${ }^{1, *}$ \\ ${ }^{1}$ Department of Gastroenterology, Hepatology and Endocrinology, ${ }^{2}$ Institute of Pathology and ${ }^{3}$ Institute for Clinical Pharmacology, \\ Charité-Universitätsmedizin Berlin, 10117 Berlin, Germany, ${ }^{4}$ Pfizer Pharma GmbH, Karlsruhe, Germany, ${ }^{5}$ Department of Neurosurgery, University \\ Hosiptal, Erlangen, Germany, ${ }^{6}$ Division of Endocrinology, Department of Medicine, University of Duisberg-Essen, Germany and ${ }^{7}$ Oldenburg, Germany
}

(Correspondence should be addressed to C J Strasburger, Division of Clinical Endocrinology, Department of Medicine, Charité-Universitätsmedizin Berlin, Schumannstr.20/21, 10117 Berlin, Germany; Email: Christian.Strasburger@charite.de)

*On behalf of the German pegvisomant investigators

\begin{abstract}
Objective: The new GH receptor antagonist pegvisomant is the most effective medical therapy to normalize IGF-I levels in patients with acromegaly. Based on currently available data pegvisomant is well tolerated; however, treatment-induced elevation of transaminases has been reported and led to the necessity for drug discontinuation in some patients in the pivotal studies. The aim of this study was to evaluate and characterize the prevalence of elevated transaminases and to describe in detail the findings in a single case who required drug discontinuation because of elevation of transaminases which emerged during treatment and who underwent liver biopsy.

Design and methods: Retrospective safety analyses were carried out on 142 patients with acromegaly receiving pegvisomant treatment in Germany between March 2003 and the end of 2004. Of these patients, 123 were documented in a post-marketing surveillance study, one case of elevated transaminases was reported spontaneously and the other patients were treated in a clinical study.

Results: Mean treatment duration with pegvisomant in the ongoing observational study at the end of 2004 was $28.3 \pm 19.9$ (S.D.) weeks. Twelve out of the 142 patients had elevated transaminases above three times the upper limit of normal, likely caused by biliary obstruction in five of the patients. All patients but one affected by elevated transaminases had been previously treated with somatostatin analogues. In six out of $142(4 \%)$ of patients, pegvisomant was permanently withdrawn because of elevated transaminases. The same number of patients showed a transient increase of transaminases with either spontaneous remission without dose modification $(n=4)$ or no re-increase of transaminases after temporary discontinuation and re-exposure $(n=2)$. The liver biopsy of one patient who was permanently withdrawn showed a chronic mild hepatitis with a mixed portal inflammation including eosinophilic granulocytes.

Conclusions: Liver function tests should be regularly followed on pegvisomant treatment. Biliary complications, which may arise from restitution of normal gall bladder motility after cessation of somatostatin analogue treatment, need to be differentiated from pegvisomant-induced abnormalities. The histological pattern of the liver biopsy performed in one of the patients showed a mild chronic active hepatitis. The lack of dose dependency and rather low frequency of elevated transaminases in those cases where a biliary disorder was excluded render this reaction an idiosyncratic drug toxicity.
\end{abstract}

European Journal of Endocrinology $154213-220$

\section{Introduction}

Acromegaly is a debilitating condition, characterized by excess of growth hormone (GH) from a pituitary tumour. Average life expectancy in patients with active acromegaly is reduced by approximately 10 years and cardiac disease is the principal cause of premature death. Treatment goals include relieving clinical symptoms, normalizations of biochemical markers, control of tumour mass and preservation/restoration of pituitary function. Adequate control of GH and insulin-like growth factor-I (IGF-I) levels results in normalization of life expectancy 
(1). Standard treatment for acromegaly consists of pituitary surgery and, if insufficient, adjuvant medical therapy and/or pituitary irradiation.

A novel GH receptor antagonist (pegvisomant) has been developed recently which, in clinical studies, is capable of normalizing serum IGF-I in over $90 \%$ of patients with active disease. Pegvisomant corrects the metabolic abnormalities of acromegaly, including insulin resistance and lipid metabolism (2-4). Normalization of serum IGF-I with pegvisomant is also associated with normalized bone metabolism (5). Uniquely among treatments for acromegaly, pegvisomant neither acts on the pituitary nor attempts to inhibit GH secretion but rather inhibits GH action. Based on the available data, pegvisomant is well tolerated. Among the possible side-effects, elevation of transaminases seems to be the most relevant. In the first clinical studies with pegvisomant, a tenfold increase of alanine aminotransferase (ALT) and aspartate aminotransferase (AST) were observed in two patients (1.2\%). However, since data regarding long-term safety with pegvisomant are limited, the aim of the present report is to summarize the cases with elevated transaminases during pegvisomant treatment seen in Germany so far and to report details of one case who had a liver biopsy and showed histological signs of chronic active hepatitis. In line with the present approved indication, most patients were treated with pegvisomant only after other forms of medical treatment were unable to normalize the disease activity of acromegaly or were not tolerated.

\section{Elevations of transaminases during pegvisomant treatment}

Up to the end of 2004, 35 acromegalic patients have been treated in Germany with pegvisomant within clinical trials and 123 acromegalic patients have been included in a non-interventional post-marketing surveillance study (including 17 patients who had already participated in a clinical trial before entering the noninterventional surveillance study). In addition, patients with active acromegaly have been on the commercial drug without being included in clinical trials.

Up to December 2004 there have been reports of elevated transaminases to more than three times the upper limit of normal (ULN) in 12 patients (seven males, five females, age $44 \pm 9$ years). Four cases were reported as adverse events from clinical trials, six cases from the non-interventional surveillance study and two were reported spontaneously from patients not included in either. Table 1 summarizes the characteristics as well as the clinical and biochemical data of these 12 patients. Alkaline phosphatase and bilirubin levels were available from only a minority of these patients. An increased level of bilirubin to 2.1-fold ULN was seen in patient no. 1. Elevated alkaline phosphatase levels were seen in patients no. 2 and no. 9 (1.4- and 1.7-fold ULN respectively).

There was one case of elevated transaminases 80.6 weeks after initiation of pegvisomant treatment. In the other 11 patients, the interval between start of pegvisomant and onset of elevated transaminases was between 6.4 and 34.7 weeks $(15.7 \pm 10.7$ weeks, means \pm S.D.). The dosage of pegvisomant at the onset of transaminases abnormalities was between 10 and $25 \mathrm{mg} /$ day $(15 \pm 5 \mathrm{mg} /$ day).Ten out of the twelve patients had previously received Sandostatin LAR (Novartis Pharma, Basel, Switzerland) as medical therapy, except for patient no. 6 who received subcutaneous octreotide and patient no. 10 who was not pretreated with somatostatin analogues. At the time of elevated transaminases, two patients were receiving a combination of pegvisomant with $30 \mathrm{mg}$ longacting octreotide every 4 weeks within a clinical trial (patients no. 8 and no. 9). Two patients had discontinued Sandostatin LAR for more than 2 years (patients no. 11 and no. 12), in six other patients the last dose of Sandostatin LAR was given between 7 and 36 weeks before the elevated transaminases.

In five patients (patient nos 1, 2, 9, 11 and 12), sonographically proven gallstone disease was present together with elevated levels of $\gamma$-GT and/or alkaline phosphatase or bilirubin; in patient no. 6 with sonographically proven gallstones these laboratory data were unavailable. In two of these patients (patients no. 9 and no. 12), bile duct stones could be verified by endoscopic retrograde cholangiography as the most obvious reason for laboratory abnormalities, suggesting biliary complications rather than a drug reaction as the reason for liver enzyme elevations. Additionally, in patient no. 2 the leading enzyme was $\gamma$-GT and gallstones were found.

During follow-up, transaminases returned to normal in all patients after 4-32 weeks (mean 12 weeks). Interestingly, in four patients, transaminases spontaneously normalized despite ongoing treatment with pegvisomant.

\section{Case study}

We report here in detail on a 43-year-old man (Table 1, patient no. 8) who presented in May 1997 in our clinic with typical clinical features of acromegaly and an elevated IGF-I. Magnetic resonance imaging demonstrated a macroadenoma of the pituitary gland with suprasellar extension. Debulking of the tumour by trans-sphenoidal surgery in June 1997 as well as stereotactic radiotherapy of the residual pituitary adenoma in 1999/2000 effectively reduced tumour mass but was not sufficient to control the GH excess. Using several medications (lanreotide, dopamine agonists), only transient and partial suppression of the residual acromegaly disease activity was achieved. Long-acting octreotide 
Table 1 Clinical and biochemical characteristics of 12 patients with elevation of liver function tests (LFT) during pegvisomant treatment.

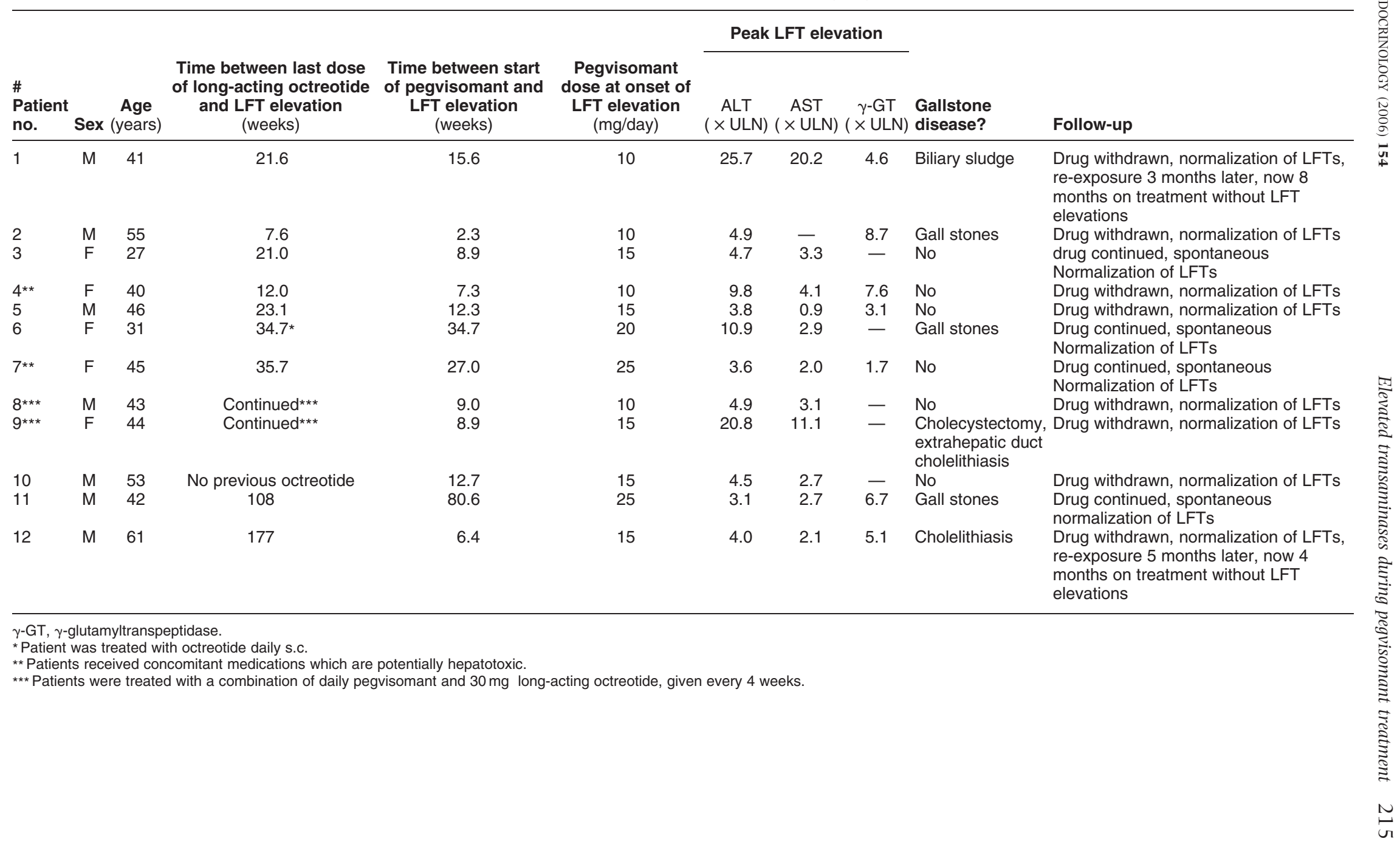


(Sandostatin LAR, $30 \mathrm{mg}$ every 28 days) also failed to reduce IGF-I levels to the normal range. The patient was then treated within a clinical trial with Somavert (pegvisomant) in combination with Sandostatin LAR (30 mg). Treatment with Somavert was initiated at a dose of $10 \mathrm{mg} /$ day s.c. and was adjusted to $15 \mathrm{mg} /$ day because of incomplete suppression of IGF-I. Treatment was well tolerated and resulted in significant improvement of clinical symptoms. The patient reported an improved sense of well-being, disappearance of paresthesias and reduced soft tissue swelling of the hands. Biochemical evaluation demonstrated normalization of IGF-I which was reduced to the age-related reference range.

Eight weeks after the start of treatment we noticed a gradual increase of the transaminases. After ALT increased fivefold above the ULN, which persisted over several weeks, we decided to discontinue treatment with Somavert. Treatment with Sandostatin LAR injections at monthly intervals was continued. $\gamma$-GT was only mildly affected. No concurrent increase in serum alkaline phosphatase was observed. Diagnostic work-up for exclusion of other hepatic diseases, including viral hepatitis and haemochromatosis, Wilson's disease, autoimmune hepatitis and $\alpha-1$ anti-trypsin deficiency was performed. Ultrasound examination showed normal echogenicity of the liver parenchyma without signs of steatosis. In addition, there was no evidence of gallstone disease. A liver biopsy was performed for further diagnostic evaluation. Histology demonstrated discrete portal fibrosis without bridging and discrete lobular hepatitis with fatty droplets in $30 \%$ of hepatocytes. The majority of the portal tracts showed a mixed inflammatory infiltrate and discrete interface hepatitis. Inflammatory cells were composed of lymphocytes, histiocytes, mast cells and eosinophilic granulocytes consistent with chronic mild active hepatitis (Fig. 1 and 2). Two months after discontinuation of

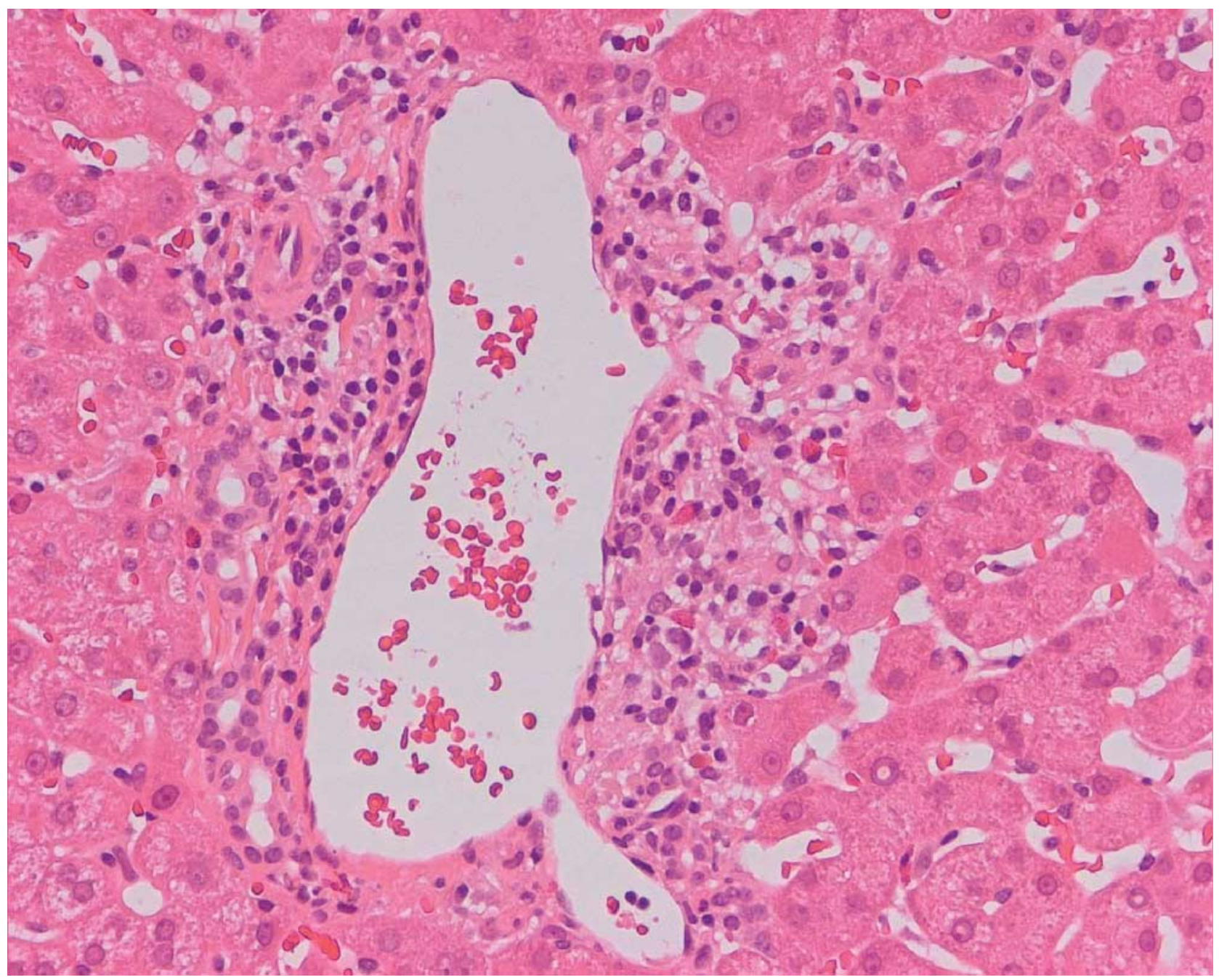

Figure 1 Portal tract (haematoxylin-eosin): mixed portal inflammation with eosinophilic granulocytes and interface hepatitis. 


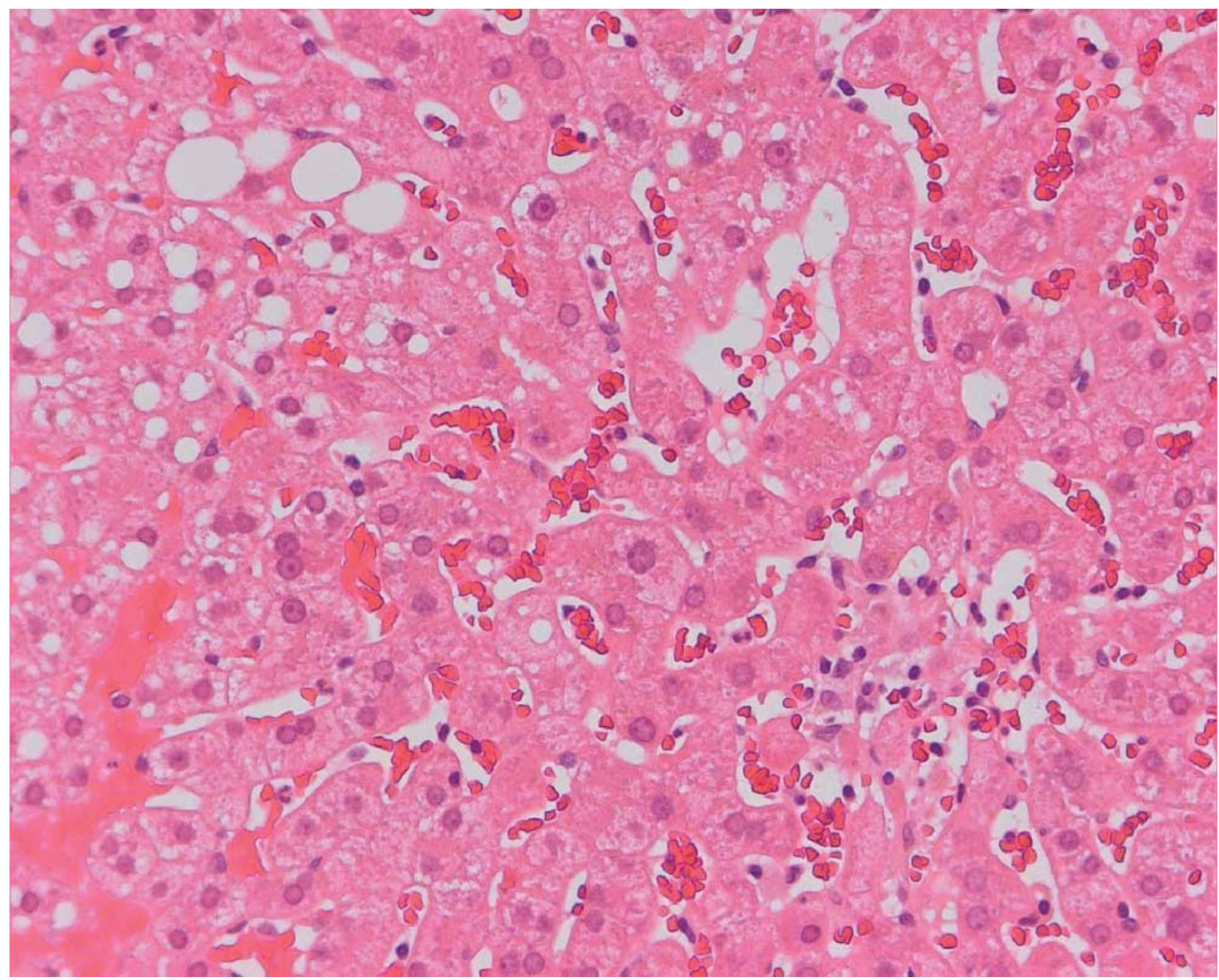

Figure 2 Lobule (haematoxylin-eosin): hepatocytes with fatty droplets and discrete lobular hepatitis with inflammatory demarcation.

pegvisomant treatment liver transaminases returned to ubinaemia, which was present before the increase of normal values without further specific therapy (Table 2). the transaminases, normalized during the hepatitis Gilbert's syndrome had previously been diagnosed in 1997 in this patient. Interestingly, mild hyperbilirepisode and reappeared after transaminases had returned to normal values.

Table 2 Biochemical and hormonal parameters in patient no. 8 before, during and after treatment with pegvisomant.

\begin{tabular}{|c|c|c|c|}
\hline \multirow[b]{2}{*}{ Treatment } & January 04 & $\begin{array}{c}\text { April } 04 \\
\text { Sandostatin LAR }(30 \mathrm{mg})\end{array}$ & June 04 \\
\hline & \multicolumn{3}{|c|}{ Pegvisomant (15 mg) } \\
\hline IGF-I (70-230 ng/ml) & 556 & 214 & 414 \\
\hline ALT $(6-43 \mathrm{U} / \mathrm{I})$ & 26 & 210 & 32 \\
\hline AST $(11-36 \mathrm{U} / /)$ & 26 & 112 & 34 \\
\hline Blood glucose fasting $(3.9-6.4 \mathrm{mmol} / \mathrm{l})$ & 5.8 & 5.7 & 5.3 \\
\hline Blood glucose $2 \mathrm{~h}(\mathrm{mmol} / \mathrm{l})$ & 6.3 & 10.2 & 5 \\
\hline AUC glucose & 15.3 & 16.9 & 16.5 \\
\hline Insulin fasting ( $\mu \mathrm{U} / \mathrm{ml})$ & 5.47 & 8.72 & 3.5 \\
\hline Insulin $2 \mathrm{~h}(\mu \mathrm{U} / \mathrm{ml})$ & 20.06 & 108.12 & 26.5 \\
\hline AUC insulin & 47.7 & 74.1 & 60.7 \\
\hline HOMA (reference 25) $(\leq 2)$ & 1.4 & 2.2 & 0.8 \\
\hline
\end{tabular}

AUC, area under the curve; HOMA, homeostasis model assessment. 
Before commencement of pegvisomant treatment an oral glucose-tolerance test showed completely normal glucose metabolism. During the period of elevation of transaminases we observed an impaired glucose tolerance according to WHO criteria (6) despite normal IGFI levels (Table 2). Two months after discontinuation of pegvisomant treatment IGF-I levels were again increased twofold above the upper limit and transaminases had returned to normal values. At that time glucose tolerance testing again showed normal results.

Concentrations of haemoglobin $\mathrm{A}_{1 \mathrm{c}}$, cholesterol, triglyceride, lipid electrophoresis, lipoprotein a, C-reactive protein levels, erythrocyte sedimentation rate, haematocrit, white blood cell count, platelet counts, blood urea nitrogen, creatinine and lactate dehydrogenase were within normal limits at baseline and did not change during treatment.

\section{Discussion}

\section{Safety and tolerability}

Based on the available data, pegvisomant is well tolerated. In the first two double-blind, placebo-controlled trials of pegvisomant for treatment of acromegaly of 46 and 112 patients, respectively, were randomized $(7,8)$. Many of the patients from these studies have subsequently been transferred to a long-term daily dosing regimen, with normalization of serum IGF-I in $97 \%$ of patients. In these studies, a tenfold increase of ALT and AST was observed in two patients $(1.2 \%)$. Both patients experienced mild fatigue and had normal bilirubin concentrations. Liver transaminases returned to normal several months after drug discontinuation. In one patient, a liver biopsy was performed revealing chronic active hepatitis of unknown aetiology. The second patient was rechallenged and transaminases rose again, proving a causative role of pegvisomant. No other significant adverse events were observed during long-term treatment (9).

Presently available data showed that the incidence of slight increases of transaminases was not different between pegvisomant- and placebo-treated patients. The increases in transaminases did not appear to be dose-related, usually occurred within 3 month of initiation of therapy and were not associated with any identifiable biochemical, phenotypic or genetic predictors. Concurrent increases in serum total bilirubin and alkaline phosphatase, which are established as indicators of serious drug-induced hepatic injury, were not observed. In many cases, increases in transaminases were sporadic and returned to normal without discontinuation of pegvisomant therapy (10).

The present report adds data from 12 patients treated in Germany with elevations of transaminases to more than three times ULN during pegvisomant treatment. In five of these patients, the presence of sonographically proven gallstone disease together with elevated levels of
$\gamma$-GT, alkaline phosphatase or bilirubin suggest biliary complications rather than a pegvisomant-induced reaction as the reason for liver enzyme elevations. In two of these patients, cholelithiasis was clearly identified as the reason for liver enzyme elevations; these patients underwent an endoscopic retrograde cholangiograpy with a therapeutical papillotomy.

After discontinuation of pegvisomant treatment, transaminases returned to normal in all patients. Interestingly, in four patients, transaminases spontaneously normalized despite ongoing treatment with pegvisomant. Additionally, in patients no. 1 and no. 12 treatment was recommenced, after temporary discontinuation of pegvisomant for 3-5 months, and no further increase of transaminases was observed.

The mechanism of pegvisomant-induced deranged transaminases remains the subject of conjecture. In order to increase the antagonist's half-life and to reduce antibody formation, a pegylated formula of the substance was developed. Hepatotoxicity has not been reported with other pegylated compounds in clinical use, and no such adverse events have been evident in any of the animal toxicology studies to date $(11,12)$. Moreover, attachment of polyethyleneglycol polymers to polypeptides is thought to reduce immunogenicity. It seems unlikely therefore that the drug formulation of pegvisomant has contributed to the hepatotoxicity observed in our patient.

Gilbert's syndrome is a benign disorder caused by insufficient enzymatic conjugation of bilirubin without alteration of liver function. Bilirubin levels normalized during the phase of acute hepatitis in the described case. It is unlikely therefore that Gilbert's syndrome contributed to the development of hepatitis. As induction of enzymes, e.g. by barbiturates, normalizes bilirubin, normalization of bilirubin levels during hepatitis was possibly secondary to inflammation-induced induction of hepatic enzymes.

\section{Glucose metabolism}

Pegvisomant was not found to induce a glycaemic effect in animal studies $(13,14)$. Furthermore, in a recent study of healthy subjects, pegvisomant was not associated with deterioration in glucose tolerance (15). GH infusion in normal subjects stimulates gluconeogenesis and lipolysis, which are mediated by the GH receptor, resulting in increased blood glucose and fatty acid levels, causing enhanced insulin secretion and sustained hyperglycaemia $(16,17)$. Similarly, acromegaly is characterized by increased glucose turnover, insulin resistance and hyperinsulinaemia $(18,19)$. Adequate control of acromegaly disease activity therefore results in improvement in glucose tolerance by normalization of $\mathrm{GH}$ excess.

Van der Lely et al. (9) investigated glucose metabolism in 160 patients treated with pegvisomant. The improvement in serum IGF-I was associated 
with a significant fall in mean fasting insulin and glucose, indicating improved insulin sensitivity. These results were confirmed by Rose \& Clemmons (20) who reported a significant progressive increase in insulin sensitivity, which was related to both dose and duration of pegvisomant treatment. Improvement of insulin sensitivity did not appear to be due to changes in body composition or a reduction of lipolysis respectively $(20,21)$.

Increased insulin resistance in the case described was possibly caused by the toxic hepatitis caused by pegvisomant. Insulin resistance is found in inflammatory liver diseases (22), which are characterized by increased production of tumour necrosis factor- $\alpha$ (TNF- $\alpha$ ) (23). As TNF- $\alpha$ induces insulin resistance by directly inhibiting signalling from the insulin receptor (24), the metabolic changes in this patient are likely to be primarily related to inflammation-mediated effects.

\section{Conclusion}

As pegvisomant is the most effective medical therapy for normalizing serum IGF-I levels, the drug represents a major advance in the treatment of acromegaly. Based on currently available data, pegvisomant is well tolerated. However, in a minority of patients increases in transaminases are observed.

The present series summarizes clinical and laboratory data from 12 German patients with elevated transaminases during pegvisomant treatment. It illustrates that in any individual case pegvisomant-induced abnormalities have to be differentiated from biliary complications seen in these patients. These may occur as a consequence of cholecystolithiasis which, after resumption of normal gall bladder contractility following discontinuation of long-acting somatostatin analogue treatment, may be moved into the biliary duct. The mechanism of pegvisomantinduced deranged transaminases remains the subject of conjecture. Because of the low frequency and the dose independence of the untoward reaction, idiosyncratic drug toxicity has to be assumed. Drug surveillance as well as basic research is needed to clearly define the association between the use of pegvisomant and hepatitis. Monitoring of liver transaminases is required during pegvisomant therapy and, beyond assessment of ALT and AST, monitoring should include $\gamma$-GT, alkaline phosphatase and potentially bilirubin levels to facilitate differentiation between hepatotoxicity and cholestatic causes of transaminase elevations.

\section{Acknowledgements}

The German Pegvisomant Observational Study is supported by a grant from Pfizer Pharma $\mathrm{GmbH}$ Karlsruhe, Germany.

\section{References}

1 Holdaway IM, Rajasoorya RC \& Gamble GD. Factors influencing mortality in acromegaly. Journal of Clinical Endocrinology and Metabolism $200489667-674$.

2 Trainer PJ, Drake WM, Perry LA, Taylor NF, Besser GM \& Monson JP. Modulation of cortisol metabolism by the growth hormone receptor antagonist pegvisomant in patients with acromegaly. Journal of Clinical Endocrinology and Metabolism $2001862989-2992$.

3 Parkinson C, Drake WM, Wieringa G, Yates AP, Besser GM \& Trainer PJ. Serum lipoprotein changes following IGF-I normalization using a growth hormone receptor antagonist in acromegaly. Clinical Endocrinology 200256 303-311.

4 Sesmilo G, Fairfield WP, Katznelson L, Pulaski K, Freda PU, Bonert V, Dimaraki E, Stavrou S, Vance ML, Hayden D \& Klibanski A. Cardiovascular risk factors in acromegaly before and after normalization of serum IGF-I levels with the GH antagonist pegvisomant. Journal of Clinical Endocrinology and Metabolism $2002871692-1699$.

5 Parkinson C, Kassem M, Heickendorff L, Flyvbjerg A \& Trainer PJ. Pegvisomant-induced serum insulin-like growth factor-I normalization in patients with acromegaly returns elevated markers of bone turnover to normal. Journal of Clinical Endocrinology and Metabolism 200388 5650-5655.

6 World Health Organization, Definition, diagnosis and classification of diabetes mellitus and its complications. In Report of a World Health Organization Consultation, part I: Diagnosis and Classification of Diabetes Mellitus. Geneva: World Health Organization, 1999.

7 van der Lely AJ, Lamberts SW, Barkan A, Pandya N, Besser G, Trainer PJ, Bonert V, Melmed S, Clemmons DR, Rose R, Vance ML, Thorner M, Zib K, Davis RJ, Bennett WF \& Scarlett JAA. A six-week, double blind, placebo controlled study of a growth hormone antagonist B2036-PEG (Trovert $^{\mathrm{TM}}$ ) in acromegalic patients. Proceedings of the 80th Annual Meeting of the Endocrine Society, New Orleans, LA, USA, 1988. Abstract OR4-1.

8 Trainer PJ, Drake WM, Katznelson L, Freda PU, Herman-Bonert V, van der Lely AJ, Dimaraki EV, Stewart PM, Friend KE, Vance ML, Besser GM, Scarlett JA, Thorner MO, Parkinson C, Klibanski A, Powell JS, Barkan AL, Sheppard MC, Malsonado M, Rose DR, Clemmons DR, Johannsson G, Bengtsson BA, Stavrou S, Kleinberg DL, Cook DM, Phillips LS, Bidlingmaier M, Strasburger CJ, Hackett S, Zib K, Bennett WF \& Davis RJ. Treatment of acromegaly with the growth hormone-receptor antagonist pegvisomant. New England Journal of Medicine $2000 \mathbf{3 4 2}$ 1171-1177.

9 van der Lely AJ, Hutson RK, Trainer PJ, Besser GM, Barkan AL, Katznelson L, Klibanski A, Herman-Bonert V, Melmed S, Vance ML, Freda PU, Stewart PM, Friend KE, Clemmons DR, Johannsson G, Stavrou S, Cook DM, Phillips LS, Strasburger CJ, Hackett S, Zib KA, Davis RJ, Scarlett JA \& Thorner MO. Longterm treatment of acromegaly with pegvisomant, a growth hormone receptor antagonist. Lancet 2001358 1754-1759.

10 CDER. Center for Drug Evaluation and Research Approval Package for: application number 21-106. Medical review(s) (for pegvisomant). Center for Drug Evaluation and Research, Food and Drug Administration web site 2003. Available at: http://www. fda.gov/cder/foi/nda/2003/21-106_Somavert_Medr_P1.pdf. Accessed 23 July 2003.

11 Drake WM, Parkinson C, Besser GM \& Trainer PJ. Clinical use of a growth hormone receptor antagonist in the treatment of acromegaly. Trends in Endocrinology and Metabolism $2001 \quad 12$ 408-413.

12 Harris JM \& Chess RB. Effect of pegylation on pharmaceuticals. Nature Reviews Drug Discovery 20032 214-221.

13 Flyvbjerg A, Bennett WF, Rasch R, Kopchick JJ \& Scarlett JA. Inhibitory effect of a growth hormone receptor antagonist (G120K-PEG) on renal enlargement, glomerular hypertrophy, and urinary albumin excretion in experimental diabetes in mice. Diabetes 199948 377-382. 
14 Segev Y, Landau D, Rasch R, Flyvbjerg A \& Phillip M. Growth hormone receptor antagonism prevents early renal changes in nonobese diabetic mice. Journal of the American Society of Nephrology $1999102374-2381$.

15 Parkinson C, Drake WM, Roberts ME, Meeran K, Besser GM \& Trainer PJ. A comparison of the effects of pegvisomant and octreotide on glucose, insulin, gastrin, cholecystokinin, and pancreatic polypeptide responses to oral glucose and a standard mixed meal. Journal of Clinical Endocrinology and Metabolism $2002 \mathbf{8 7}$ 1797-1804.

16 Rizza RA, Mandarino LJ \& Gerich JE. Effects of growth hormone on insulin action in man. Mechanisms of insulin resistance, impaired suppression of glucose production, and impaired stimulation of glucose utilization. Diabetes 198231 663-669.

17 Rosenfeld RG, Wilson DM, Dollar LA, Bennett A \& Hintz RL. Both human pituitary growth hormone and recombinant DNA-derived human growth hormone cause insulin resistance at a postreceptor site. Journal of Clinical Endocrinology and Metabolism $1982 \mathbf{5 4}$ $1033-1038$

18 Roelfsema F \& Frolich M. Glucose tolerance and plasma immunoreactive insulin levels in acromegalics before and after selective transsphenoidal surgery. Clinical Endocrinology $1985 \quad 22$ $531-537$.

19 Biering H, Knappe G, Gerl H \& Lochs H. Diabetes-Häufigkeit bei Akromegalie und Cushing-Syndrom. Acta Medica Austriaca 2000 $2727-31$
20 Rose DR \& Clemmons DR. Growth hormone receptor antagonist improves insulin resistance in acromegaly. Growth Hormone and IGF Research $200212418-424$.

21 Drake WM, Rowles SV, Roberts ME, Fode FK, Besser GM, Monson JP \& Trainer PJ. Insulin sensitivity and glucose tolerance improve in patients with acromegaly converted from depot octreotide to pegvisomant. European Journal of Endocrinology $2003149521-527$.

22 Hui JM, Sud A, Farrell GC, Bandara P, Byth K, Kench JG, McCaughan GW \& George J. Insulin resistance is associated with chronic hepatitis $\mathrm{C}$ virus infection and fibrosis progression. Gastroenterology $2003 \mathbf{1 2 5}$ 1695-1704.

23 Nelson DR, Lim HL, Marousis CG, Fang JW, Davis GL, Shen L, Urdea MS, Kolberg JA \& Lau JY. Activation of tumor necrosis factor-alpha system in chronic hepatitis $\mathrm{C}$ virus infection. Digestive Diseases and Sciences $1997 \mathbf{4 2} 2487-2494$.

24 Hotamisligil GS, Murray DL, Choy LN \& Spiegelman BM. Tumor necrosis factor alpha inhibits signaling from the insulin receptor. PNAS $1994914854-4858$.

25 Matthews DR, Hosker JP, Rudenski AS, Naylor BA, Treacher DF \& Turner RC. Homeostasis model assessment (HOMA): insulin resistance and $\beta$-cell function from fasting plasma glucose and insulin concentrations in man. Diabetologia $198528412-419$.

Received 5 August 2005

Accepted 25 October 2005 